\title{
INNOVATING A FLEXIBLE CONCEPT BASED CURRICULUM IN A COURSE: AN EXPERIENCE USING FRACTAL MODEL
}

\author{
Larisa Enríquez Vázquez, Universidad Nacional Autónoma de México, Mexico
}

\section{Summary}

Fractal is an educational model that tries to respond to the new learning contexts in which we find ourselves, which are characterized by the need to learn and update knowledge continuously and constantly and with the opportunity to access a large number of options for learning and training through the use of technologies, computer networks and digital environments, among others. The fractal model considers four interrelated elements but one element particularly stands out; it is the curriculum based on concepts that allows to expand and integrate different areas of knowledge to a specific, initial perspective. In addition, Fractal presents aspects that can be linked to connectivism and rhizomatic learning, through a concrete proposal of flexible learning design, which can be useful for formal and non-formal courses. The following Master's program at the University of La Sabana, in Colombia, presents an experience applying the model in a close context (https:/www.unisabana.edu.co/programas/posgrados/centro-de-tecnologias-para-laacademia/maestria-en-innovacion-educativa-mediada-por-tic-virtual/nuestro-programa/).

\section{Introduction}

Fractal is an educational proposal to face some of the challenges and demands that today's society expects universities to address. To do this, it considers flexible and open teaching models in which formal and non-formal education converge. In 2017, Enriquez referring to several authors, such as Bates (2011), Tünnerman (2003), González Casanova (2001), points out the need to adapt university models to those that are more in line with the current context we live in, considering pedagogical methods centred on collective and self-directed work which allow, through curricular flexibility, personal learning paths with interdisciplinary approaches (Enríquez, 2017; p.375). The model has four elements that contribute to the following four dimensions: curricular flexibility, adaptability to environment, academic relevance and accessibility, in several ways. The elements proposed to achieve this goal are based on concepts curriculum, student-centred teaching, academic openness and promotion of heutagogy. The continuous execution of each one of them shows a Fractal figure (Figure 1). 


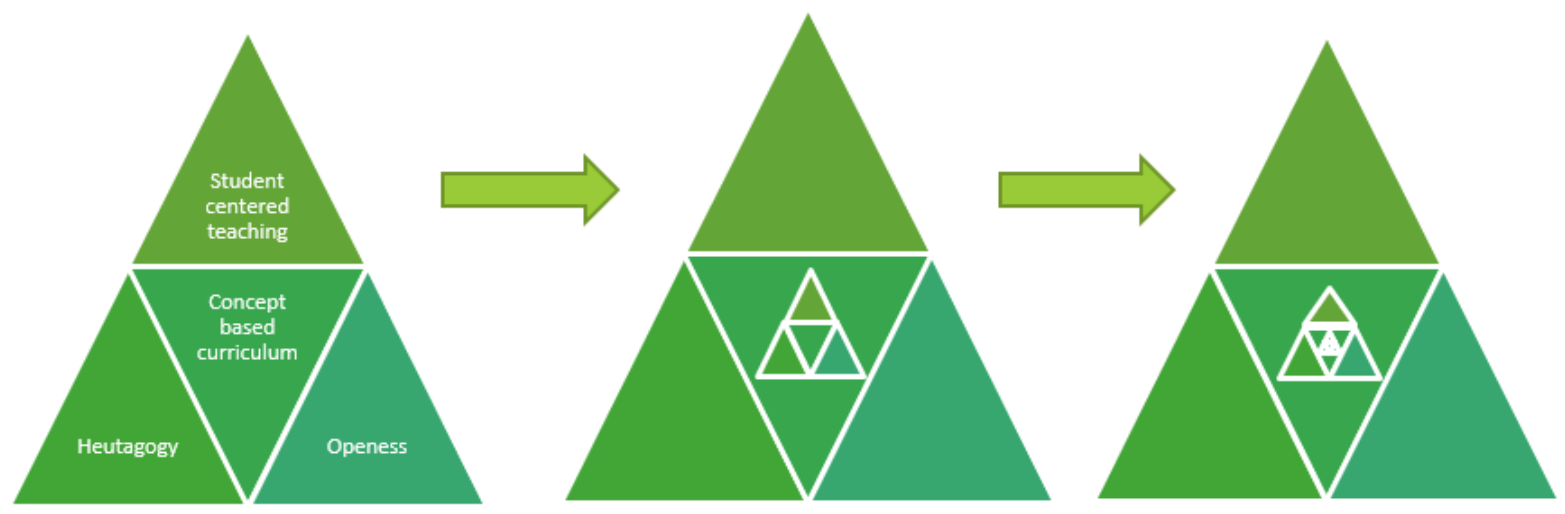

Figure 1. Fractal's elements and its iterations

\section{Concept based curriculum}

It is common to find in traditional models of education that the content of the academic programs is designed by topics or units which has generated, among other things, extensive detailed programs that, in the vast majority of cases, isolate a topic from others. However, if we consider the essential concepts of a syllabus, we can optimize teaching and learning by concentrating on deep understanding of each term which, depending on the context to which it is translated, takes on new meanings.

According to Erickson (2008), concept-based curriculum design not only reduces curricular load in a course, but also helps to focus teaching on broad and relevant situations at the same time that it enhances more flexible learning methods and strategies.

Erickson herself points out that concept-based design, when it is connected to prior knowledge, brings relevance and meaning to students' learning while causing students to process facts and skills on deeper intellectual levels, as they relate to facts, strategies and skills linked to key concepts, their generalizations and principles. It also increases the motivation for learning by involving personal knowledge and increases the fluency of language when students explain and defend their own understanding with reliable information. (Erickson, 2008; p.83).

On the other hand, Siemens (2005) and Cormier (2008) point out that learning that is sought from a pre-established curriculum transmits the idea that knowledge is static and closed, in which information is hardly updated or responds to new contexts. Enriquez points out that concepts are cognitive units of meaning, that arise from the interaction with the environment and the previous knowledge we have, and it is through continuous interaction with ourselves and others that we can create new knowledge and new concepts (Enríquez, 2017; p.377). In this sense, Fractal presents a curriculum based on concepts that, for the students, can be represented by conceptual maps.

Under this perspective, curriculum changes constantly when new concepts are introduced that arise from the interaction with different people, groups and resources. All of these new concepts are selected freely and independently by each of the students with the guidance of 
the teacher. While there is a starting point for the development of the fractal, represented by a concept map that presents a general idea of the teacher to address the course, new concept maps emerge from the specific context in which learning takes place, the prior knowledge and the specific interests of each student. The initial concept map is called Concept domain, while the new concept maps are called Personalized concept domains (see Figure 2).

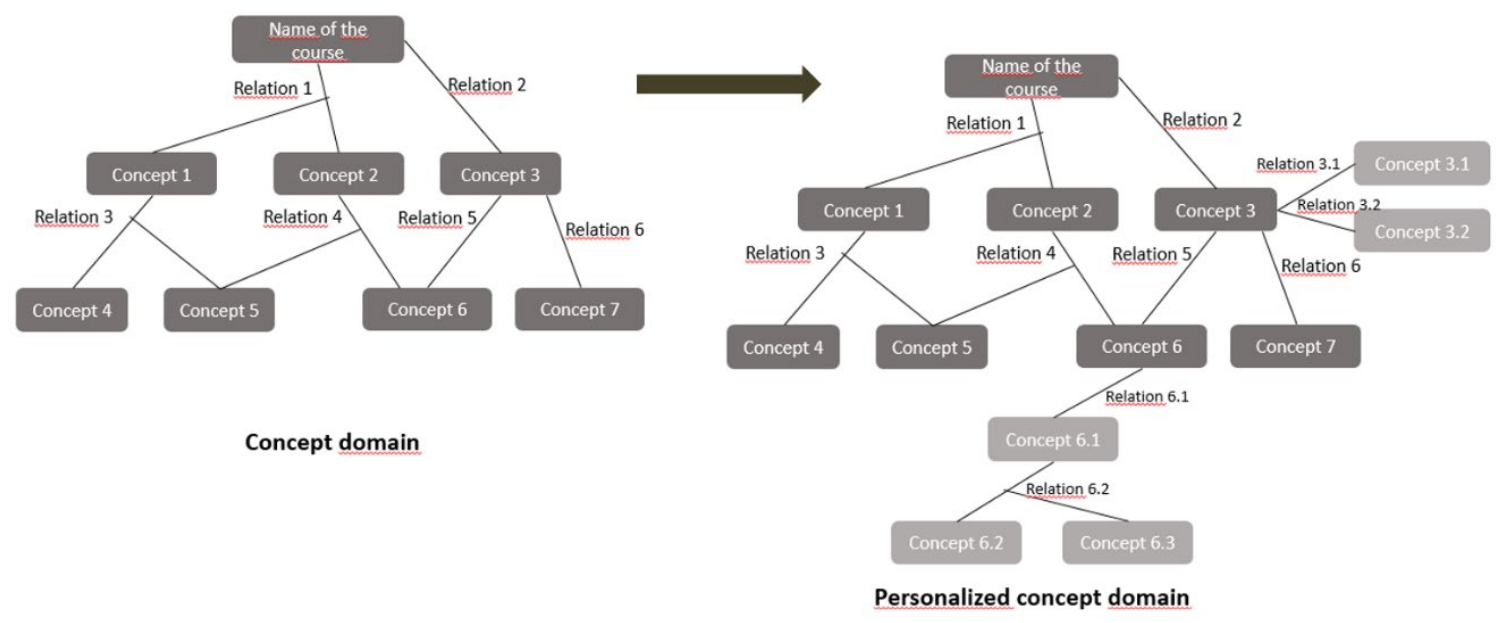

Figure 2. Concept domain and $1^{\text {st }}$ iteration

Although Fractal tries to open up new ways to explore more significative, open and flexible experiences in which formal and non-formal education are intertwined, it is difficult for traditional schools and programs to make dramatic changes to their teaching models. In this sense, Fractal can also be used to design flexible courses within a specific academic degree program to enhance curricular flexibility through self-determination of students.

\section{An online experience using Fractal}

The Master's degree in Educational Innovation mediated by ICT (Information and Communication Technologies), from the University of La Sabana, in Colombia, is a recently created online master's degree, which began activities in 2018. Within the Master's program, there is a course called "Innovation Project II", for which this author was invited to design and teach the content. Although the general structure of the program maintains a slightly more traditional structure, it was possible to propose a way to approach the course in a more flexible and connectivism way using the Fractal model. In this sense, the following was taken into considerations for the course:

- To have a conceptual domain that would guide the analysis of at least five concepts.

- To invite students to develop a personal work log for self-tracking, self-reflection and self-evaluation.

- To provide materials and experiences close to students' personal project and interests.

- To search for communities of experts on topics of interest to students.

The course spanned over twelve weeks with three registered students. The Concept domain that was presented at the beginning of the course and considered five main concepts 
(educative innovation, educative research, models, processes and indicators). The initial relations suggested among these concepts can be seen in Figure 3.

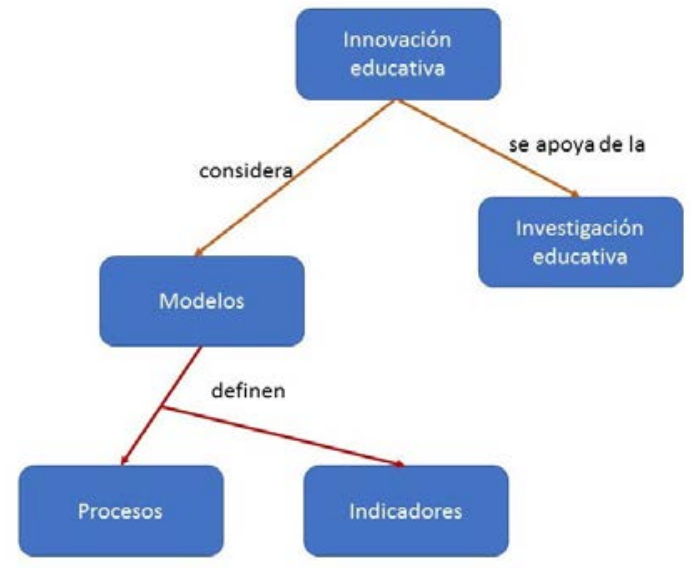

Figure 3. Course's Concept domain map

A brief introduction together with some suggested readings was given to review each of the concepts, to start analysis and reflection. Likewise, guiding questions were included to help students to work in a general way on the understanding of the concept, as well as to anchor it in their personal projects so that they could refine and improve it. For the specific review of students' understanding of the concepts, they were invited to work continuously on their personalized concept domain maps. Figure 4 and Figure 5 show a student's first and second iteration for the Concept domain. The yellow square emphasizes the concepts that were modified and widened, after completing some readings and having interactions through the virtual classroom. Figure 6 shows the fourth iteration where the student's progress can be seen as she is advancing in the review of the different concepts proposed in the Concept domain.

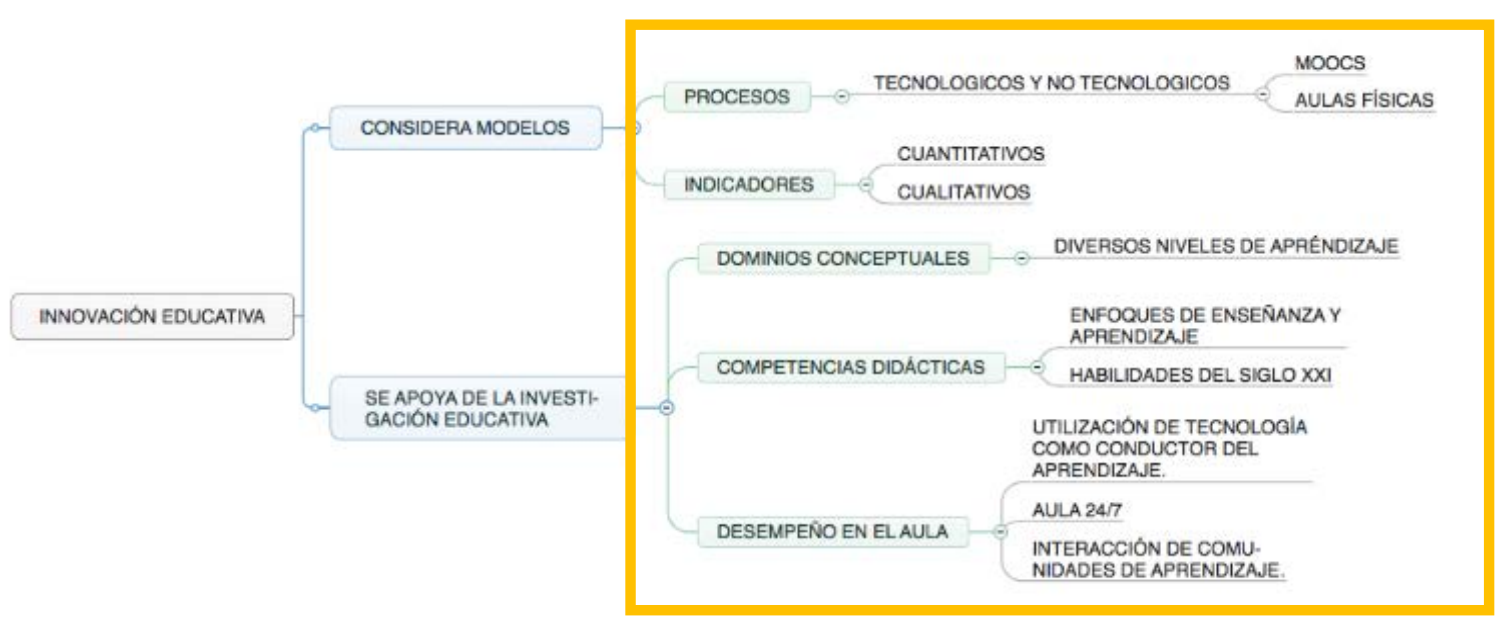

Figure 4. Student A, personalized concept domain, $1^{\text {st }}$ iteration 


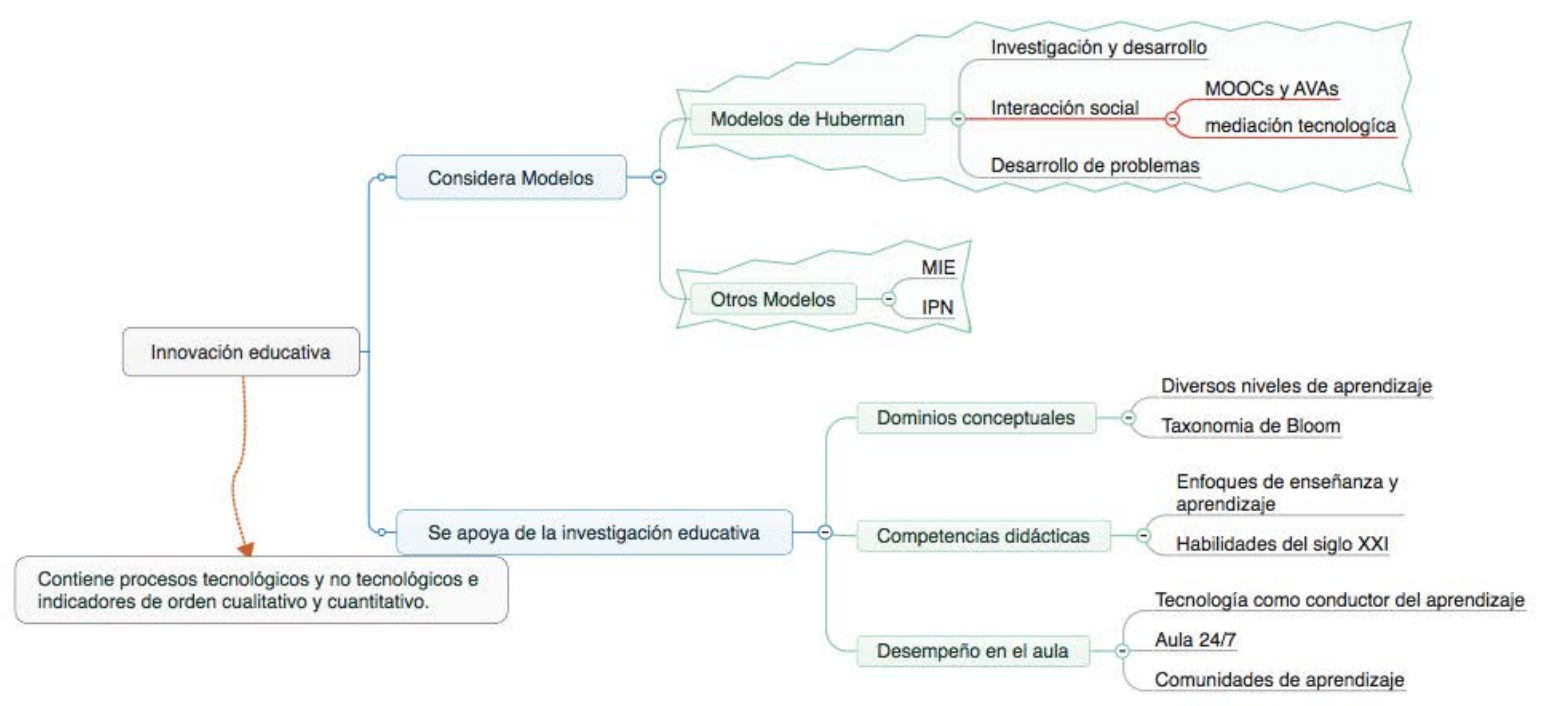

Figure 5. Student A, personalized concept domain, $2^{\text {nd }}$ iteration

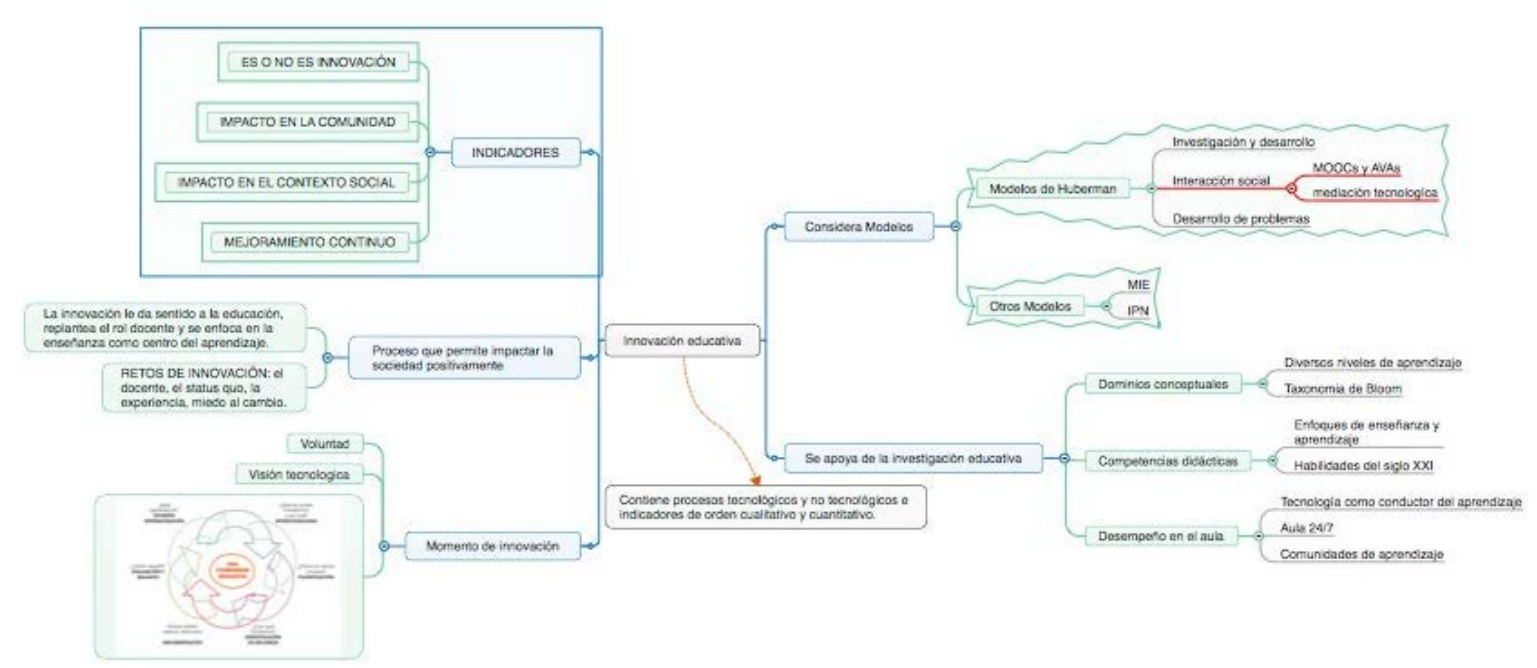

Figure 6. Student A, personalized concept domain, $4^{\text {th }}$ iteration

On the other side, we may expect that working individually with the Concept domain should bring different Personalized concept domains. In Figure 7 we can see another student's $2^{\text {nd }}$ iteration personalized concept domain, after she studied the concept called Educative research. In the concept map presented, it can be seen that the student classified the different kinds of educational research. Some of them were classified from the perspective of the methodologies used, some of them were classified according to the kind of variables they manage, or according to the moment in which they take place. The student even integrated specific documents for different concepts to support her point of view. Nevertheless, the personalized concept domain not only proves the approach and specific interests that student B had, but it is also evidence of the personal trajectories that each student has. It further shows the different understandings that take place in this learning experience. While the $2^{\text {nd }}$ iteration of student A personalized concept domain mentions different educational areas in which research is taking place (she even points out some examples), student's B personalized concept domain brings a variety of classifications that have been used in educational research. 
It is interesting to see that both student $\mathrm{C}$ and student $\mathrm{A}$ included in some way the topic they are working with as part of their personal research project (in the case of student $\mathrm{C}$, digital resources and in the case of student A, MOOC's).

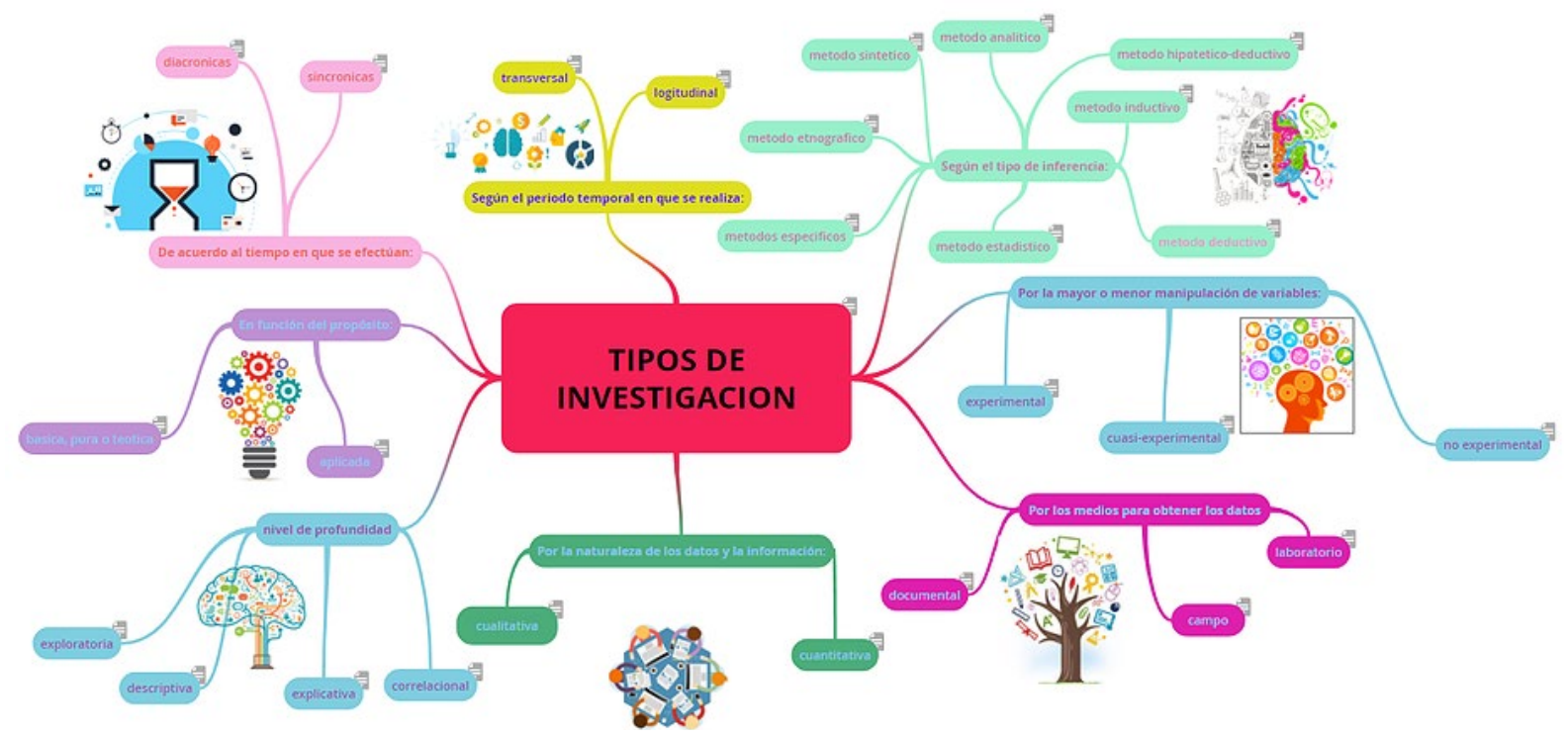

Figure 7. Student B, personalized concept domain, $2^{\text {nd }}$ iteration

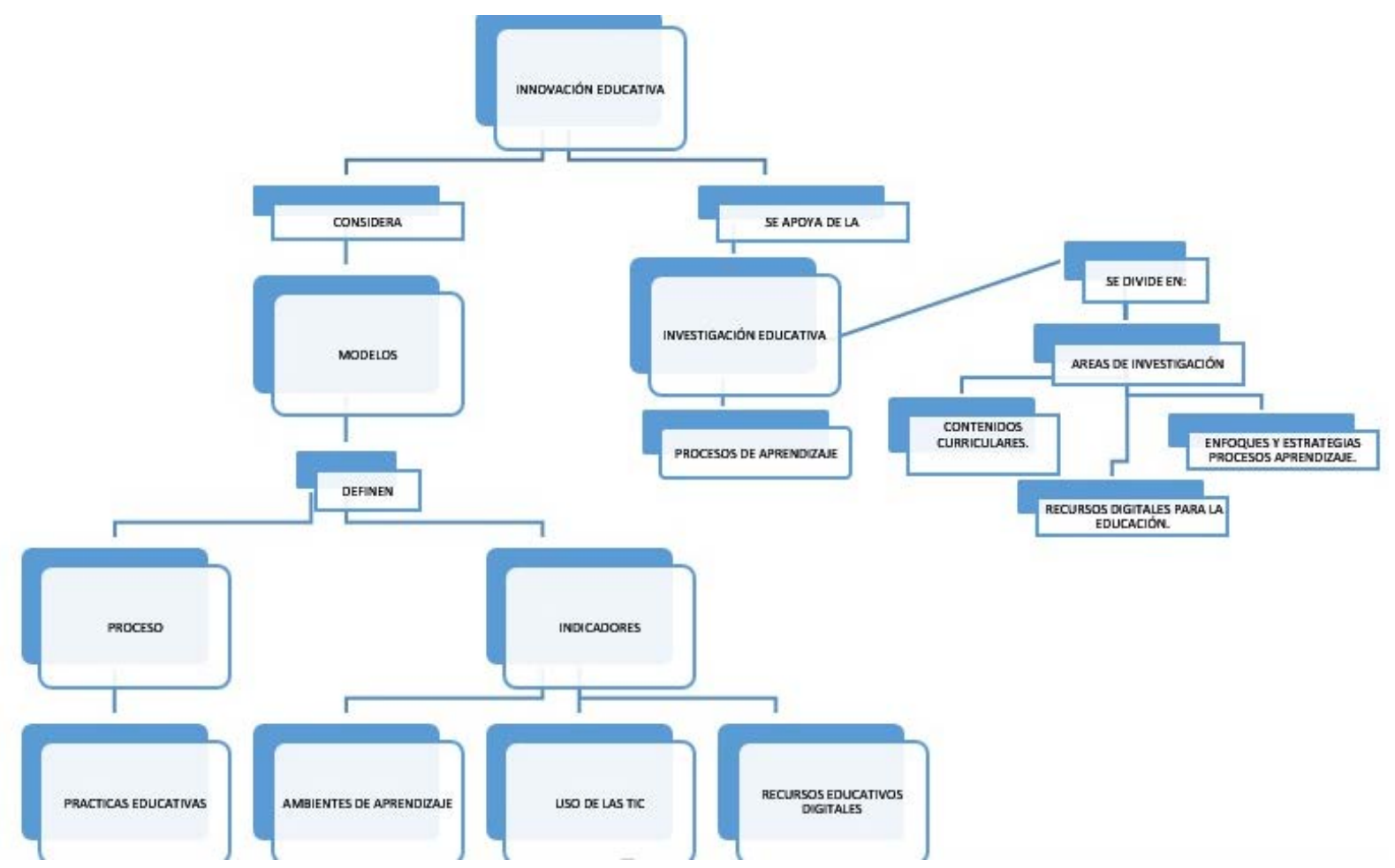

Figure 8. Student $C$, personalized concept domain, $2^{\text {nd }}$ iteration

\section{Results}

As has been said, the Fractal educational model is composed of four elements that aim to promote student-centred teaching, curricular flexibility, students' self-determination and the possibility of connecting with other communities. The first two elements which are curriculum based on concepts and students' self-determination were those that were 
exercised to a greater degree while the last two elements were driven to a lesser degree. The students presented, through the personalized concept domains, both knowledge and misinterpretation of the relationships between different concepts. Likewise, it was found that the specific interests of the students (in this case, the topic of the research project they are developing) were also reflected in these personalized conceptual domains.

On the other hand, the research activities that were focused on landing the new knowledge into the degree project, helped to identify problems and doubts about the research topic. This then led to the possibility of connecting with a group of subject matter experts.

Although the Fractal model might present some of the chaotic and rhizomatic principles to which connectivism and rhizomatic learning point, in this case, however, the networks of connections do not reflect the interactions with different communities or with resources but the level of understanding and deepening that is obtained from a concept. At the same time, if we analyse the transformations that happen in each of the personalized conceptual domains, we obtain evidence of the introspective exercise that each student does.

\section{Conclusions}

The Fractal model tries to open up new opportunities for universities to explore alternatives for more significant academic experiences. Through this model, particularly considering the concept-based and flexible curriculum design, it is possible to offer a divergent view of the relationships that exist between a group of concepts. Furthermore, it presents the personal learning trajectories through which each student has travelled and how the student considers moving forward.

Also, Fractal through the concept domain, presents a solution to one of the problems that some course designers have found in designing a connectivist or rhizomatic courses. Despite the interesting and rich proposals that connectivism and rhizomatic learning represent, at the end, it is very difficult to design a course under one of these two pedagogical approaches. In this sense, Fractal sets a starting point for a course that it is just this, a starting point for a living, exploratory and personal learning experience.

\section{References}

Bates, T. (2011, November 11). European report on the future of learning. Online learning and teaching resources [Blog post]. Retrieved from http://www.tonybates.ca/2011/11/11/european-report-on-the-future-of-learning/

Cormier, D. (2008, June 3). Rhizomatic education: Community as curriculum. Dave's educational blog [Blog post]. Retrieved from http://davecormier.com/edblog/2008/06/03/rhizomatic-education-community-ascurriculum/

Enríquez, L. (2017). Fractal: An educational model for the convergence of formal and nonformal education. Open Praxis, 9(4), 375-386. http://dx.doi.org/10.5944/openpraxis.9.4.699 
Erickson, H. L. (2008). Stirring the head, heart, and soul: Redefining curriculum, instruction, and concept-based learning ( $3^{\text {rd }}$ ed.). Thousand Oaks, CA: Corwin Press.

González Casanova, P. (2001). La universidad necesaria en el siglo XXI. Ed. Era.

Siemens, G. (2005). Connectivism: A learning theory for the digital age. International Journal of Instructional technology and distance learning, 2(1). Retrieved from http://www.itdl.org/journal/jan_05/article01.htm

Tünnermann B. C. (2003). La Universidad Latinoamericana ante los retos del siglo XXI. México: Unión de Universidades de América Latina. 